\title{
PROF, POSSO USAR O FACEBOOK?: EXPERIÊNCIA DE INTEGRAÇÃO DE MÍDIA SOCIAIS EM CLASSE
}

\author{
PROFE, ¿PUEDO USAR EL FACEBOOK?: \\ EXPERIENCIA DE INTEGRACIÓN DE MEDIOS SOCIALES EN CLASE
}

\author{
TEACHER, MAY I USE THE FACEBOOK?: \\ AN EXPERIENCE INTEGRATING SOCIAL MEDIA IN THE CLASSROOM
}

\author{
Kadhiny Mendonça de Souza POLICARPO ${ }^{1}$ \\ Juliana Cristina Faggion BERGMANN²
}

RESUMO: A sociedade contemporânea tem sofrido constantes transformações com a nova era digital e no panorama ao qual nos encontramos é praticamente impossível desvincular a tecnologia das nossas atividades cotidianas, em que se mostra cada vez mais presente. Sendo a escola um microcosmo dessa mesma sociedade (BOURDIEU, 2001), em que toda transformação que nela ocorre reflete-se igualmente na educação. Dessa forma, as redes sociais, utilizadas de maneira massiva como fonte de comunicação e entretenimento fora da escola por alunos e professores, tornam-se um recurso pedagógico de imediato acesso, quando em ambiente escolar. Tais grupos ou espaços específicos na internet, que permitem partilhar dados e informações, de caráter geral ou específico, das mais diversas formas (textos, arquivos, imagens fotos, vídeos) (LIMA, 2011), passam, portanto, a ser usados como recurso de aprendizagem em sala de aula. Assim, este trabalho apresenta o relato de uma experiência sobre a integração de mídias em aulas de língua espanhola para no $1^{\circ}$ ano do Ensino Médio no colégio de aplicação da UFSC, utilizando-se da rede social facebook como ferramenta pedagógica. Em uma experiência desenvolvida no estágio supervisionado, a rede serviu de canal de comunicação para a apresentação e compartilhamento de informações sobre as atividades propostas em sala de aula de língua estrangeira, seguindo a metodologia do enfoque por projetos.

PALAVRAS-CHAVE: Redes sociais. Tecnologia. Língua estrangeira. Facebook. Recurso pedagógico.

RESUMEN: La sociedad contemporánea ha sufrido constantes transformaciones con la nueva era digital, y en el panorama en el cual nos encontramos es prácticamente imposible desvincular la tecnología de nuestras actividades cotidianas en donde se muestra cada vez más presente. La escuela es como un microcosmo de esa misma

\footnotetext{
${ }^{1}$ Universidade Federal de Santa Catarina (UFSC), Florianópolis - SC - Brasil. Graduada no curso superior de Letras Espanhol - Licenciatura pela Universidade Federal de Santa Catarina (UFSC) (2017). Participante do grupo de pesquisa Tema Didático - Tecnologia, Educação e Materiais Didáticos (GPTema) do Programa de Pós-Graduação em Educação (PPGE/UFSC). Bolsista do Programa Institucional de Bolsa de Iniciação à Docência (PIBID). ORCID: <http://orcid.org/0000-0002-20976647>. E-mail: kadhinymendonca@gmail.com

2 Universidade Federal de Santa Catarina (UFSC), Florianópolis - SC - Brasil. Professora do Departamento de Metodologia de Ensino (MEN), e do Programa de Pós-Graduação em Educação (PPGE/UFSC), na linha Educação e Comunicação (ECO). ORCID: <http://orcid.org/0000-0002-05355279>. E-mail: juliana.bergmann@ufsc.br
} 
sociedad (BOURDIEU, 2001) y cada transformación que ocurre se refleja de la misma forma en la educación. Así, las redes sociales, utilizadas de manera masiva como fuente de comunicación y entretenimiento fuera de la escuela por los alumnos y profesores, se tornan un recurso pedagógico de acceso inmediato en el ambiente escolar. Tales grupos o espacios específicos en internet, que permiten compartir datos $e$ informaciones, de carácter general o específicos, de las más variadas formas (textos, archivos, imágenes, fotos, vídeos) (LIMA, 2011), pasan entonces a ser usados como recursos de aprendizaje en la sala de clase. De esa manera, en este trabajo se presenta un relato de una experiencia sobre la integración de medias en el aula de lengua española para el primer año de la secundaria en el colégio de aplicação de la UFSC y utiliza la red social facebook como herramienta pedagógica. En una experiencia desarrollada en la pasantía, la red sirvió de canal de comunicación para la presentación y la distribución de informaciones sobre las actividades propuestas en la clase de lengua extranjera según la metodología de enfoques por proyectos.

PALABRAS CLAVE: Redes sociales. Tecnología. Lengua extranjera. Facebook. Recursos pedagógicos.

ABSTRACT: Nowadays society has been suffering frequent transformations with the new digital era and, in the outlook where we find ourselves it is practically impossible to unlink the technology from our daily activities, where it is more present each day. The school being a microcosmos from this same society (BOURDIEU, 2011), which all transformation that happens reflecting equally on education. This way, the social medias used in a massive way as a source of communication and entertainment out of the school for students and teachers, become an immediate pedagogical access resource, within school contexts. Such groups or specifics spaces on the internet that allow shared data and information, from general or specific characters, from several formats (text, file, image, photo, video) (LIMA, 2011), therefore start being used as teaching resources in the classroom. Likewise, this article discusses experiences through a report about media integration in Spanish language class to a group from the 1st year in High School at the Colégio de Aplicação da UFSC, using the social media facebook as a pedagogic tool. This experience was developed at the supervised internship, the social media served as a communication channel for presentation and information sharing about the activities proposed in foreign language class, following the projects methodology.

KEYWORDS: Social media. Technology. Foreign language. Facebook. Pedagogical resource.

\section{Sociedade, Tecnologia e Mídias}

A linearidade, unitariedade e lentidão de pensamento são características que já não fazem mais parte da atual Geração "Z", geração dos plurais, conhecidos também por serem nativos digitais, muito familiarizados com a internet, com o compartilhamento de arquivos e com a instantaneidade de comunicação e informação. 
Viver nessa aldeia global na era da informação, como menciona Pérez Gómez (2015), provoca em seus integrantes alterações na maneira de se expressar, de consumir, de se comunicar e até mesmo de pensar. A sociedade contemporânea, formada por grande parte pela geração Z (pessoas nascidas entre 1988-2010), nos mostra cada vez mais indícios dessas mudanças e da interação entre sociedade-tecnologia.

O grande estopim para essas mudanças foi a invenção da internet, chamada por Pérez Gómez (2015, p. 8) de "Janela para o mundo", ferramenta que, de acordo com o autor, "configura e molda o que vemos e como vemos, o que queremos e o que projetamos", $(2015$, p. 8) por seu poder e onipresença. Esta tecnologia rodeia de forma decisiva a vida da população contemporânea, utilizando-se da facilidade - palavra chave para descrevê-la - nos acessos e trocas de informações, tornando quase tudo o que buscamos instantâneo.

Outra vertente, provavelmente a segunda na linha de importância e utilidade da internet é a comunicação. De acordo com Trinta (2003), definiu-se o termo comunicação como "pôr em comum", "compartir", "compartilhar", "produzir modificações no comportamento e na atitude de uma ou mais pessoas.", definições coerentes quando analisado o papel que a internet vem exercendo nas últimas década. Alguns meios tradicionais de comunicação não deixaram de ser amplamente utilizados; entretanto, essas novas plataformas ganharam um considerável espaço na sociedade, influenciando nossas relações interpessoais e nossa comunicação com o outro. Para isto surgiram as redes sociais, ou mídias sociais, que são grandes redes de comunicação responsáveis pela transmissão, agilidade, capacidade e alcance das informações imediatas.

As mídias sociais digitais quebram com várias barreiras antes enfrentadas pela comunicação, e hoje, facilitadas pela internet. Com a interatividade virtual anulamos a interferência do espaço físico, de maneira que a distância e o tempo deixaram de ser um empecilho e passaram a ser aspectos pouco relevantes. Com a ajuda dos smartphones, essas redes ficam mais expostas e mais propensas ao uso, de uma maneira praticamente contínua e com poucas interrupções, uma vez que podem ser acessadas de qualquer lugar a qualquer instante.

Todas as mudanças ocorridas na sociedade são refletidas na escola, por ela representar o seu microcosmo (BOURDIEU, 2001). Sendo assim, como uso das redes sociais é quase em sua totalidade de maneira massiva, abrangendo grande parte da sociedade, é imprescindível que não repercute ambiente escolar. Com o intuito de 
adaptar-se aos tempos da internet essas mídias sociais, quando colocadas em sala de aula, tornam-se recursos pedagógicos.

Os incríveis avanços técnicos em eletrônica, informática e redes, vêm criando um novo campo de ação, novos processos sociais, métodos de trabalho, mudanças culturais profundas, novos modos de aprender e de perceber o mundo (e portanto de intervir nele), com repercussões significativas no campo da educação, a exigir transformações radicais no métodos de ensino e nos sistemas educacionais. (BELLONI, 2002, $\mathrm{s} / \mathrm{p})$

Pensando-se assim, este trabalho apresenta um relato de experiência utilizando o facebook como ferramenta de apoio pedagógico no estágio supervisionado de língua espanhola na turma de Primeiro ano do Ensino Médio do Colégio de Aplicação, da Universidade Federal de Santa Catarina (UFSC).

Optou-se pelo uso desta mídia como uma estratégia para estruturação de intenções educativas (ZABALA, 1998), visto que é uma das redes sociais mais acessadas pelos os alunos, auxilia ao objetivo de proporcionar um maior contato com a língua estrangeira em situações reais de uso, trazendo mais significado ao ensino, construindo um novo espaço de reflexão e intervenção educacional. Nas palavras do autor,

Promover a atividade mental auto estruturante que permita estabelecer o máximo de relações com o novo conteúdo, atribuindo significado de maior grau possível e fomentando os processos de metacognição que facilitem assegurar o controle pessoal sobre os conhecimentos e os próprios processos durante a aprendizagem. (ZABALA, 1998, p. 65)

Com isso, Zabala Mostra que esta proximidade dos conteúdos propostos com a utilização da mídia, geram um processo cognitivo em relação a aprendizagem do aluno, estruturando e esclarecendo de forma intelectual as atividades voltadas para a tecnologia.

\section{Uso de mídias digitais na prática educativa na escola campo de estágio}

As tecnologias digitais de informação e comunicação, também conhecidas como TDICs, vêm atribuindo um importante papel no processo de ensino/aprendizagem. A utilização desses recursos pode potencializar este processo, além de contribuir para resultados mais significativos do mesmo. Para trabalhar com as TDICs não basta simplesmente implementá-las, é importante que se busque novas metodologias para que não caia no âmbito das "novas tecnologia, com velhas metodologias" como fomenta 
Pérez Gómez (2015). As tecnologias digitais de informação e comunicação estão intimamente ligadas à metodologias que abarque: colaboração, pesquisa, autoria, capacidade de resolver problemas e autonomia.

\section{TDICs na escola}

O uso das tecnologias digitais de informação e comunicação no Colégio de Aplicação da Universidade Federal de Santa Catarina é de alguma maneira facilitado por conta de sua estrutura. A escola conta com o wi-fi (proveniente da universidade), no qual cada aluno pode acessar utilizando seu usuário e senha. Há o laboratório de informática equipado com computadores e projetor, além das salas de língua estrangeiras, que também dispõe de projetores, todos conectados à internet. Para um fácil acesso à internet em sala de aula, sem a necessidade de deslocamento físico, a escola disponibiliza do Laboratório Interdisciplinar de Formação de Professores (LIFEUFSC), onde é possível fazer a reserva de equipamentos digitais (Tablets e notebook) para a utilização em sala de aula. Ação utilizada para esta práctica docente.

Ademais, de todos estes recursos disponibilizados pelo colégio, todos alunos de espanhol do primeiro ano do ensino médio dispõem de smartphones pessoais, sendo muitas vezes utilizados no lugar de todos os equipamentos mencionados anteriormente. Estes fatores, e facilidades, foram decisivos na escolha de implementar as mídias sociais em classe como recurso pedagógico durante o período de estágio supervisionado.

\section{Facebook na escola}

A rede social Facebook, muito utilizada pelos jovens essencialmente por razões sociais, dentro do âmbito escolar é vista como um vilão, como um componente que prejudica o ensino. A rede não tem nenhum objetivo de ensino, porém se vê muito utilizada informalmente pelo jovens com objetivos relacionados a assuntos estudantis, como formar grupos de trabalhos e projetos, ou resolver outros tipos de questões que abarque o âmbito escolar, como fomenta Porto e Santos (2014).

Entretanto, na atualidade as mídias digitais estão presentes de maneira que há a integração dos espaços físicos e online, constituindo assim, "novos espaços para o conhecer." (PORTO; SANTOS, 2014). Com o intuito de aliar a rede a favor do ensino, e de acordo com Porto e Santos (2014), "permitir o desenvolvimento de capacidades e 
estratégias de ensino/aprendizagem mais dinâmicas e interativas, abertas e criativas, possibilitando uma maior participação", pensou-se em criar um grupo fechado. Como reforça Porto e Santos (2014) os grupos "são espaços online criados com um objetivo/ interesse particular, e que podem ser úteis para estudantes e professores trabalharem de forma colaborativa" onde, atividades poderiam ser elaboradas e compartilhadas no mesmo ambiente, construído assim, de acordo com Belloni (2002), um novo espaço de reflexão e intervenção educacional.

\begin{abstract}
Assim, e sendo as redes sociais espaços coletivos e colaborativos de comunicação e de troca de informação, podem facilitar a criação e desenvolvimento de comunidades de prática ou de aprendizagem desde que exista uma intencionalidade educativa explícita. (PORTO;SANTOS, 2014, s/p)
\end{abstract}

Outro ponto pelo qual se optou pelo uso do Facebook, foi para poder mostrar aos alunos que esta ferramenta tão presente em suas vidas pode ter uma utilização mais crítico-criativa neste caso, como auxílio para acercamento e aquisição da língua espanhola. Mostrar-lhes que se pode fazer o uso da tecnologia em sala de aula a favor do espanhol, expandindo o contato com o idioma fora de sala de aula, esta que ocorre de maneira limitada em um curto encontro semanal.

O interessante de se trabalhar com as redes é que além do conteúdo linguístico que se utiliza, por ser uma ferramenta escrita e que é movida pela linguagem, nos possibilita abranger os conteúdos atitudinais. Ativar o lado crítico social do aluno de maneira que ele possa avaliar, escolher e descartar os conteúdos de maneira que seja relevante para o seu propósito. Por ser uma redes internacionalmente conectada é imprescindível que haja os mais variados tipos de conteúdos, sendo estes, muitas vezes de caráter superficial e sem embasamento, que necessita uma filtragem crítica-social por parte do leitor. Fundamento a esta prática nos princípios a teoria de mídia educação.

A mídia-educação é uma condição de educação para a "cidadania instrumental e de pertencimento", para a democratização de oportunidades educacionais e para o acesso e produção de saber, o que contribui para a redução das desigualdades sociais. (FANTIN, 2011, $\mathrm{s} / \mathrm{p})$

Rede social, como o nome já expressa, uma ligação (rede) social com a sociedade por intermédio da comunicação, conceitos inteiramente interligados. Como fomenta Fantin (2011), "toda prática educativa é também uma prática comunicativa, não existe educação em comunicação", desta maneira, o uso do facebook de forma massiva é de 
prática comunicativa, passando a uma prática educativa (e também comunicativa) quando em sala de aula.

\section{Projeto de Integração das Mídias em sala de aula de LE}

A partir das observações na primeira etapa do estágio de docência, percebeu-se o uso em demasia de smartphones para pesquisa e utilização em atividades propostas pela professora regente, além de presenciar a autonomia dos alunos nas pesquisas em sala de aula através do uso dos recursos tecnológicos. Pensando-se nisso, e constatando o perfil criativo e comunicativo da turma, viu-se a possibilidade de se trabalhar com a metodologia de enfoque por projetos aliando a mídia social "facebook" na prática educativa, com o objetivo de incluir o uso de uma rede social em sala de aula que interessava ao grupo e de aumentar o contato dos alunos com a língua espanhola, já que poderiam acessá-la mesmo quando não estivessem na escola, de maneira que o processo de ensino-aprendizagem fosse mais significativo e interessante.

\section{Metodologia}

A aprendizagem embasada por projetos é a metodologia que requer que os alunos planejem, criem e avaliem um projeto que responda às necessidades em uma determinada situação problema, nas palavras do pioneiro desta metodologia, Dewey (1952), "todo conhecimento verdadeiro deriva de uma necessidade". Esta prática é embasada no construtivismo (PIAGET, 1920; VYGOTSKY, 1934), que fomenta que as pessoas que constroem suas aprendizagens a partir dos conhecimentos prévios e experiências obtidas através da participação ativa do aluno durante o seu desenvolvimento e da interação do sujeito com o outro. Com o intuito de desenvolver a autonomia do grupo, optou-se por este enfoque, já que o aluno pode alcançar os objetivos buscando seu próprio caminho, sendo o protagonista da sua aprendizagem. A partir disto, a aprendizagem torna-se significativa, quando o indivíduo toma as rédeas e participa do processo de construção do seu próprio conhecimento.

Assumir o comando de seu próprio desenvolvimento, algo que é necessário não apenas para aqueles que deseja tornar-se pensadores líderes, mas para todos os cidadãos numa sociedade qual os indivíduos têm que definir e redefinir seus papéis ao longo de uma duração de vida. (PAPERT, 1994, p. 29) 
Outro ponto que contribuiu para a escolha desta metodologia foi o perfil do grupo, visto que o processo do estágio supervisionado é dividido em dois momentos durante o ano letivo. Um primeiro momento de observação da aula da professora supervisora e o segundo momento, onde as estagiárias lecionam ${ }^{3}$. Nesta primeira etapa de observação, notou-se o caráter criativo do grupo, característica que deu ainda mais suporte para a escolha de se trabalhar por projetos, já que nela o aluno tem essa abertura para utilizar, praticar e desenvolver a criatividade, podendo selecionar habilidades, usufruindo de seus potenciais individuais.

\section{Escolha Temática}

O material didático "Enlaces", o livro didático do PNLD adotado pela escola, traz inúmeras temáticas a serem trabalhadas durante o semestre do estágio supervisionado. Porém, como o livro foi utilizado apenas como norteador das aulas, foi adotado um único tema transversal, neste caso "El Medioambiente".

A escolha da temática transversal é de extrema importância, pois é este que apoia o verdadeiro conteúdo a ser transmitido, o linguístico, no referente caso a língua espanhola. Esta, trabalhada de maneira que envolveu o entorno social dos alunos, abordando a conteúdo de forma significativa, levando a uma melhor compreensão do mesmo.

As atividades devem partir de situação significativas e funcionais, a fim de que o conteúdo possa ser aprendido com a capacidade de poder utilizar quando seja conveniente. Por isso é imprescindível que esse conteúdo tenha sentido para o aluno, deve saber para o que serve e que função tem, ainda que apenas seja útil para poder realizar uma aprendizagem nova. (ZABALA, 1998, p. 84)

A temática foi explorada em dois grandes projetos, organizados em etapas, nas quais teriam que pesquisar acerca do lugar em que vivem. Um dos primeiros passos do primeiro projeto foi conhecer o seu próprio bairro, atividade que lhes permitiu refletir sobre o mesmo, trabalhando o senso crítico e a análise do objeto. Já o segundo projeto,

${ }^{3}$ Estágio supervisionado I - matéria no primeiro semestre do ano letivo, no qual os futuros docentes observam as aulas da professora supervisora. Esta observação é participativa, pois ocorre o contato com os alunos e ao final do semestre, a escrita de um relatório crítico reflexivo. Estágio Supervisionado II matéria do segundo semestre, no qual o graduando assume o posto de professor e leciona um determinado número de aulas. 
carta à diretora, os fez refletir sobre os mesmo pontos entretanto, com o enfoque nos desafios presentes na escola.

\section{Experiência}

A proposta de utilização da rede social foi bastante receptiva por parte dos alunos, e após fazer a introdução do projeto, foi então criado o grupo na plataforma, no qual os alunos participaram da escolha do nome relacionado com a temática do semestre, "Haciendo más por el medioambiente".

No primeiro projeto, foi realizado uma sequência didática desenvolvida em quatro encontros, nos quais os alunos realizaram postagens de atividades no Facebook referentes às etapas do projeto para que se alcançasse o objetivo do produto final: a criação de um evento na plataforma. Este evento tinha o intuito de encontrar uma solução para a problemática presente no bairro dos alunos, sendo essas expostas através de um vídeo-denúncia. A etapa do vídeo-denúncia, começou com a separação dos alunos em seis grupos, divididos a partir de seus bairro/região da cidade de Florianópolis. O objetivo era encontrar um problema ambiental significativo para sociedade local e a partir disto, criar o vídeo mostrando tal impasse. Todas essas etapas com as postagens na rede.

Já o segundo projeto, seguiu na mesma linha da temática meio ambiente, porém voltada para realidade cotidiana dos alunos, a escola, pois segundo Zabala (1998), todas as atividades propostas em sala de aula devem partir de situações significativas e funcionais, a fim de que os alunos sejam capazes de absorver o conteúdo de maneira conveniente e produtiva. Para realização deste projeto também foi aplicada uma sequência didática, partindo de um texto introdutório que direcionou os alunos a elaborar uma entrevista sobre os problemas ambientais da escola, entrevistando pessoas que também estivessem vivenciando o meio escolar. Da mesma forma que o projeto anterior, todas as atividades foram postadas na plataforma Facebook porém neste projeto, diferentemente da anterior, o corpus final não foi postado no grupo do facebook. O projeto consistia em uma carta colaborativa que foi elaborada via outro mecanismo - google docs - e que quando finalizada, impressa e entregue ao destinatário.

Sibilia (2012) crítica que o uso das redes informatizadas pelos jovens é algo quase automático e inconsciente, que no ato de comunicar-se em linha não os faz pensar no que dizem, "vão mandando o que sai", exemplifica a autora. Acrescenta ainda que "quando se escreve uma carta, toma-se tempo para lê-la, para corrigi-la; nas condições 
atuais, entretanto, dissolve-se não apenas o código, mas também a própria comunicação". O grupo na plataforma Facebook nos permite editar as postagens, o que nos proporciona um momento de segundo contato com as produções textuais, permitindo-lhes refletir sobre os erros então sinalizados, e alterar as postagens de maneira que gerasse uma segunda versão da atividade.

A receptividade dos alunos em relação à utilização da rede foi de uma maneira geral colaborativa e imediata, todas as sequências utilizando o grupo teve uma ótima aceitação e proatividade por parte dos alunos, que a partir da escrita online começaram a utilizar recursos de escrita como o teclado digital em língua espanhola, facilitando a comunicação e correção da idioma. Outra ressalva foi a possibilidade de livre acesso e interação com atividades elaboradas pelos outros colegas, onde há a interação instantânea. A experiência de utilização de outra plataforma - google docs - aliada com a página do facebook no intuito de servir de material de pesquisa para o corpus final do projeto teve um resultado satisfatório na atividade, já que os alunos a partir das entrevistas postadas, delimitaram os principais pontos a serem questionados na hora de elaborar carta.

\section{Considerações finais}

A oportunidade de assumir o papel de professora neste projeto, que utiliza as ferramentas tecnológicas a favor do ensino de língua espanhola, foi de fato muito significativa na formação como profissional, pois foi um momento de experimentação e de pôr em prática toda a teoria estudada e pesquisada na graduação. A metodologia de enfoque por projeto possibilitou dar liberdade aos alunos em suas escolhas, trabalhando suas autonomias. Da mesma forma, nos deu liberdade como professoras na hora de planejar a sequência didática, podendo utilizar da experimentação, e no dito caso, a integração da mídia social facebook em classe. Experiência, esta, que ocorreu de maneira satisfatória, cumprindo com os objetivos desejados.

Por contar com uma estrutura gratificante, não houve nenhum grande problema relacionado ao manuseamento ou funcionamento da plataforma. Por outro lado, o uso do facebook como recurso didático nos ajudou em alguns fatores que não poderiam ser abarcados em sala de aula, principalmente em dois significativos momentos: Quando os alunos não conseguiam terminar as atividades até o final da aula, eles tinham a oportunidade de estar postando no grupo no mesmo dia até determinado horário. $\mathrm{O}$ 
segundo ponto positivo que conseguimos perceber após o uso, era quando os alunos faltavam aula, eles tinham a possibilidade de estar interagindo, sabendo e comentando nas atividades dos colegas, de maneira que não ficavam descontextualizado e totalmente sem a avaliação da atividade feita do dia. Havia apenas uma aluna que não tinha acesso a rede, pois seu login e senha ficavam gravado no computador de casa, controle optado pelos seus pais, porém ela fazia todas as atividades logada ao facebook de sua companheira e assinava seu nome ao final, ação que não afetou de nenhuma forma o andamento do projeto.

Sendo o professor uma profissão social, Libâneo (2013) defende que, como a sociedade se modifica com o passar dos anos, repercute nas ações docentes, uma vez que a ação é em prol da sociedade. Desta forma, é imprescindível que a educação se adeque às tecnologias à cada dia mais presentes e utilizadas.

\section{REFERÊNCIAS}

BELLONI, M. L. Mídia-educação ou comunicação educacional? Campo novo de teoria e de prática. In: BELLONI, M. L. et al (Org.). A formação na sociedade do espetáculo. São Paulo: Edições Loyola, 2002. p. 27-46.

BELLONI, M. L. O que é mídia-educação. Campinas: Autores Associados, 2001.

CASTELLS, M. Internet e sociedade em rede. Por uma outra comunicação: mídia, mundialização cultural e poder. In: TRINTA, A. Comunicação à época da internet. Rio de janeiro: Record, 2003.

FANTIN, M. Mídia-educacão: aspectos históricos e teórico-metodológicos. Olhar de Professor, v. 14, n. 1, p.27-40, jul., 2011. DOI: 10.5212/olharprofr.v.14i1.0002.

LIBÂNEO, J. C. Didática. 2. ed. São Paulo, SP: Cortez, 2013

PAPERT, S. A Máquina das Crianças: repensando a escola na era da informatica. Porto Alegre: Artes Médicas, 1994. 210 p.

PÉREZ GÓMEZ, A. L. Educação na era digital: a escola educativa. Porto Alegre: Penso, 2015. 192p.

PORTO, C.; SANTOS, E. orgs. Facebook e educação: publicar, curtir, compartilhar [online]. Campina Grande: EDUEPB, 2014. ISBN 978-85-7879-283-1.

SIBILIA, P. Redes ou paredes: a escola em tempos de dispersão. Rio de Janeiro: Contraponto, 2012. 222 p.

ZABALA, A. A prática educativa: como ensinar. Porto Alegre: Artmed, 1998. p. 224. 


\section{Como referenciar este artigo}

POLICARPO, Kadhiny Mendonça de Souza.; BERGMANN, Juliana C. F. Prof., posso usar o facebook?: experiência de integração de mídia sociais em classe. Rev. EntreLínguas, Araraquara, v.4, n.1, p. 31-42, jan./jun. 2018. E-ISSN: 2447-3529. DOI: 10.29051/rel.v4.n1.2018.10918.

Submetido em: 19/01/2018

Revisões requeridas: 05/03/2018

Aprovado em: 12/04/2018 